\title{
COMPARISON BETWEEN PADC AND FNTD NEUTRON DETECTOR SYSTEMS IN BLIND TESTS
}

\author{
E. G. Yukihara ${ }^{1,2, *}$, M. S. Akselrod ${ }^{3}$, V. Fomenko ${ }^{3}$, J. Harrison ${ }^{3}$, M. Million ${ }^{4}$, F. Assenmacher ${ }^{1}$, \\ A. Stabilini ${ }^{1,5}$ and K. Meier ${ }^{1}$ \\ ${ }^{1}$ Department of Radiation Safety and Security, Paul Scherrer Institute, 5232 Villigen PSI, Switzerland \\ ${ }^{2}$ Physics Department, Oklahoma State University, Stillwater, OK 74074, USA \\ ${ }^{3}$ Landauer Inc., Crystal Growth Division, 7231/2 Eastgate St., Stillwater, OK 74074, USA \\ ${ }^{4}$ Landauer Europe, 9 rue Paul Dautier CS 60731, 78457 Vélizy-Villacoublay, France \\ ${ }^{5}$ Politecnico di Milano, Dipartimento di Energia, via la Masa 34, 20156 Milan, Italy \\ *Corresponding author: eduardo.yukihara@okstate.edu
}

\begin{abstract}
The objective of this study was to compare a neutron dosimetry system based on polyallyl diglycol carbonate (PADC) detectors with a new system based on $\mathrm{Al}_{2} \mathrm{O}_{3}: \mathrm{C}, \mathrm{Mg}$ fluorescence nuclear track detectors (FNTD). The irradiations, performed as part of an intercomparison organized by the Physikalisch-Technische Bundesanstalt (PTB), Germany, were on a PMMA phantom with ${ }^{252} \mathrm{Cf}$ or ${ }^{241} \mathrm{Am}$-Be source, usually with the phantom surface perpendicular to the radiation beam $\left(0^{\circ}\right.$ angle), and with $H_{\mathrm{p}}(10)$ values between 0.3 and $7 \mathrm{mSv}$. One ${ }^{252} \mathrm{Cf}$ irradiation was performed at $30^{\circ}$ angle, and one with an additional $1 \mathrm{mSv}$ gamma irradiation. The results showed an agreement between the two techniques with an average and maximum difference between PADCs and FNTDs of 1.5 and $22 \%$, respectively, if one compares only cases of doses $>1 \mathrm{mSv}$. For one of the irradiation conditions with dose of $0.9 \mathrm{mSv}$, use of the incorrect calibration factor for the FNTD $\left({ }^{252} \mathrm{Cf}\right.$ instead of $\left.{ }^{241} \mathrm{Am}-\mathrm{Be}\right)$ led to reported values $\sim \times 2$ larger than the given doses, due to low statistics in the determination of the ratio between ${ }^{6} \mathrm{Li}-$ doped glass and polyethylene neutron converters. Although the FNTD track analysis algorithm may need further development, the results presented here demonstrate the feasibility of the FNTD technology and indicate areas requiring improvements.
\end{abstract}

\section{INTRODUCTION}

Neutron dosimetry remains challenging because of the large variation in the interaction cross-sections used for neutron detection (mostly elastic collisions with protons and inelastic collisions with nuclei such as ${ }^{6} \mathrm{Li}$ and ${ }^{10} \mathrm{~B}$, resulting in secondary charged particles), the large variation in the neutron fluence to air kerma and dose equivalent (ambient or personal) conversion coefficients, and the wide neutron energy spectrum, ranging from thermal neutrons up to hundreds of $\mathrm{MeV}$, depending on the neutron source and moderation $^{(1)}$.

Track-etch detectors are frequently used for passive neutron dosimetry ${ }^{(1)}$. The technique is based on the registration of neutron-induced recoil protons and other nuclei in materials, such as polyallyl diglycol carbonate (PADC), enlarged by a chemical or electrochemical etching and quantified by optical microscopy or light scattering ${ }^{(2)}$. Advantages include the permanent track registration after etching, and the relatively flat energy response in the region between $200 \mathrm{keV}$ and $10 \mathrm{MeV}$ neutron energy ${ }^{(3,4)}$. Disadvantages include the need for etching, the strong dependence of the sensitivity and background on the material properties ${ }^{(5)}$, which requires strict quality control, and the fact that the detectors are not reusable.

Fluorescent Nuclear Track Detectors (FNTDs) is a new technique for neutron dosimetry, based on the registration of tracks in $\mathrm{Al}_{2} \mathrm{O}_{3}: \mathrm{C}, \mathrm{Mg}$ crystals specially grown for this purpose. Instead of chemical damage, the registration process is the radiochromic transformation of color centers in the FNTD crystal due to ionizations produced by neutron-induced charged particles ${ }^{(6)}$. The radiation-induced color centers are imaged by confocal microscopy ${ }^{(7)}$, resulting in images of the single tracks without chemical etching. A neutron dosimeter system was developed combining the FNTDs with neutron converters ${ }^{(8)}$, since $\mathrm{Al}_{2} \mathrm{O}_{3}$ itself is not sensitive to neutrons. Advantages include the fact that the radiochromic transformation is stable up to $600^{\circ} \mathrm{C}$, but can be reversed by a thermal treatment ${ }^{(9)}$ or by optical erasure using a pulsed UV laser, making the detectors reusable.

The goal of this work was to compare the two technologies (PADCs and FNTDs), taking advantage of the neutron dosimetry intercomparison organized by the Physikalisch-Technische Bundesanstalt (PTB), Germany. Intercomparisons are organized 


\section{E. G. YUKIHARA ET AL}

routinely and used not only for quality assurance, but also to evaluate new technologies ${ }^{(10)}$.

\section{METHODOLOGY}

PADC detectors (Table 1) used by PSI are the TASTRAK $^{\circledR}$ (Track Analysis Systems Ltd.) in polyamide (PA) holders (Figure 1), which provide a fast neutron converter layer ${ }^{(11)}$. The holder allows for ${ }^{6} \mathrm{LiF}$ chips to be placed on two opposite sides of the PADC as thermal neutron converters (currently not used in the dose calculation). After irradiation the detectors were etched using a $6.25 \mathrm{M} \mathrm{NaOH}$ solution for $2 \mathrm{~h} 50 \mathrm{~min}$ at $85^{\circ} \mathrm{C}$.

The FNTDs (Table 1) consists of $\mathrm{Al}_{2} \mathrm{O}_{3}: \mathrm{C}, \mathrm{Mg}$ single crystals placed on a holder (Figure 1) in contact with two neutron converters, polyethylene (PE) for fast neutrons and ${ }^{6} \mathrm{Li}$-loaded glass for thermal neutrons, as well as a Teflon ${ }^{\circledR}$ (PTFE) for gamma signal subtraction ${ }^{(8)}$. The holders also contain three positions for optically stimulated luminescence detectors (not used). Before assembly, the FNTDs were bleached with a pulsed UV laser and read to ensure low residual background $\left(<1 \mathrm{track} / \mathrm{mm}^{2}\right)$ and good surface quality.

Irradiations were performed in the PTB irradiation room $(7 \mathrm{~m} \times 7 \mathrm{~m} \times 6.5 \mathrm{~m})$ at $3.25 \mathrm{~m}$ above ground with the detectors on the surface of a $30 \mathrm{~cm} \times 30 \mathrm{~cm} \times$ $15 \mathrm{~cm}$ PMMA phantom, using either a ${ }^{252} \mathrm{Cf}$ source or a ${ }^{241} \mathrm{Am}-\mathrm{Be}$ source (see nominal conditions in Table 3). One ${ }^{252} \mathrm{Cf}$ irradiation was performed with a $30^{\circ}$ angle and one set of detectors was given an additional gamma dose from a ${ }^{137} \mathrm{Cs}$ source.

The PADCs and FNTDs were calibrated at PSI's accredited laboratory with ${ }^{241} \mathrm{Am}-\mathrm{Be} H_{\mathrm{p}}(10)=$ $3 \mathrm{mSv}$ in reference conditions, on the surface of a $30 \mathrm{~cm} \times 30 \mathrm{~cm} \times 15 \mathrm{~cm}$ ISO water phantom. ${ }^{(12)}$ The calibration was also verified by irradiation with ${ }^{241} \mathrm{Am}-\mathrm{Be}$ at Landauer Inc. (Glenwood calibration laboratory) with $5 \mathrm{mSv}$, with $3 \mathrm{mSv}$ bare ${ }^{252} \mathrm{Cf}$ irradiation at PSI, and with $1 \mathrm{mSv}$ and $3 \mathrm{mSv}$ bare ${ }^{252} \mathrm{Cf}$ irradiation at SCK.CEN Belgium.

PADC detectors were analyzed using the TASLIMAGE Neutron Dosimetry System (Track Analysis Systems
Ltd.) in the same conditions used for routine dosimetry at PSI. The system performs automatic track analysis and calculates the track density after rejection of artefacts based on a proprietary algorithm. The dose is calculated by simple comparison with the track density of calibration detectors. For the used PADC batch, the calibration factor was 400 tracks $\mathrm{cm}^{-2} \mathrm{mSv}^{-1}$. Each detector analysis takes $\sim 30 \mathrm{~s}$. The ratio between the track counts under the ${ }^{6} \mathrm{LiF}$ chip and the PA converters (Li/PA ratio) were determined by an independent scan.

The FNTDs were analyzed at Landauer, Europe using a confocal laser scanning microscope system developed by the company and proprietary analysis algorithm ${ }^{(8)}$. Result for the calibration detectors are shown in Table 2. The ratio between the Li-loaded glass and $\mathrm{PE}$ is referred to as $\mathrm{Li} / \mathrm{PE}$ ratio. The FNTD response under different converters is dependent on the neutron energy ${ }^{(13)}$. Based on the data of Table 2 and previous results, the calibration factor for the ${ }^{241} \mathrm{Am}-\mathrm{Be}$ spectrum was adopted if the $\mathrm{Li} / \mathrm{PE}$ ratio was $<0.4$, and for the ${ }^{252} \mathrm{Cf}$ spectrum if the $\mathrm{Li} / \mathrm{PE}$ ratio was $\geq 0.4$. If the $\mathrm{Li} / \mathrm{PE}$ ratio $<0.5$

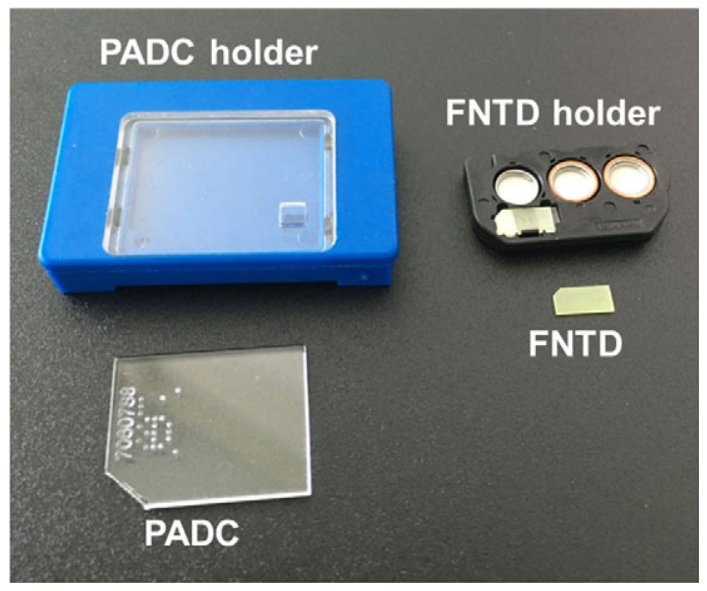

Figure 1. PADC and FNTD detectors used in this study.

Table 1. Characteristics of the PADC detectors and FNTDs used in this study.

\begin{tabular}{|c|c|c|}
\hline & PADC & FNTD \\
\hline Dimensions & $20.0 \mathrm{~mm} \times 25.0 \mathrm{~mm} \times 1.5 \mathrm{~mm}$ & $4.0 \mathrm{~mm} \times 8.0 \mathrm{~mm} \times 0.5 \mathrm{~mm}$ \\
\hline Manufacturer & Track Analysis Systems Ltd. & Landauer Inc. \\
\hline \multirow[t]{3}{*}{ Converters } & $2 \mathrm{~mm}$ polyamide & ${ }^{6}$ Li-loaded glass: $(830 \pm 25) \mu \mathrm{m}$ \\
\hline & $3 \mathrm{~mm} \times 3 \mathrm{~mm} \times 0.9 \mathrm{~mm}$ & Polyethylene (PE): $2 \mathrm{~mm}$ \\
\hline & ${ }^{6} \mathrm{LiF}$ chips & PTFE \\
\hline Preparation & - & Bleached with pulsed UV laser bleaching \\
\hline Post-irradiation etching & $6.25 \mathrm{M} \mathrm{NaOH}$ solution for $2 \mathrm{~h} 50 \mathrm{~min}$ at $85^{\circ} \mathrm{C}$ & - \\
\hline Scanned area & $1.0 \mathrm{~cm}^{2}$ & $2.76 \mathrm{~mm}^{2}$ per converter \\
\hline
\end{tabular}




\section{COMPARISON BETWEEN PADC AND FNTD NEUTRON DETECTOR SYSTEMS}

and the $\mathrm{CV}$ of the ratio $>30 \%$ we considered the energy determination as 'uncertain' (see irradiation \#16, Table 3) and used the ${ }^{252} \mathrm{Cf}$ calibration factor.

\section{RESULTS AND DISCUSSION}

Table 3 summarizes the results for the various irradiation conditions. The FNTD track densities were $\times 2.1$ higher than the PADC track densities for the ${ }^{252} \mathrm{Cf}$ neutron spectrum, and $\times 4.8$ higher for the ${ }^{241} \mathrm{Am}-\mathrm{Be}$ neutron spectrum. These results indicate the strong energy dependence of FNTD in comparison with PADC, in agreement with the calibration data (Table 2) and the energy response of these detectors $^{(3,13)}$. The data demonstrates an agreement within $\pm 22 \%$ between the PADCs and FNTDs, except for doses $<1 \mathrm{mSv}$ (irradiation \#15 and 16, see more below).
The ratios between reported and delivered doses were similar for PADCs and FNTDs, with deviations within $\pm 30 \%$, except irradiation $\# 15$ because of the low dose, and irradiation \#16 in the case of the reported FNTD result; using the correct calibration factor, the result agree with the PADC results. Furthermore, the additional $1 \mathrm{mSv}$ gamma dose in irradiation \#11 did not cause a problem for either PADCs or FNTDs.

For unirradiated PADC detectors, no dose was observed, indicating the good performance of the TASLIMAGE system background discrimination algorithm (data not shown). For the FNTDs, the mean dose of the unirradiated detectors was $0.08 \mathrm{mSv}$, with a standard deviation of $0.09 \mathrm{mSv}$. For a single FNTD a dose of $0.28 \mathrm{mSv}$ was reported. It is not clear at this point if this is due to the influence of cosmic rays during transport or detector fluorescence background.

Table 2. FNTD calibration for irradiation in various facilities.

\begin{tabular}{lccrr}
\hline Source & Dose (mSv) & Sensitivity of PE converter area (tracks cm $\left.{ }^{-2} \mathrm{mSv}^{-1}\right)$ & $\mathrm{Li} / \mathrm{PE}$ & sd Li/PE \\
\hline Am-Be (PSI) & 3 & 1740 & 0.24 & 0.14 \\
Am-Be (Landauer) & 5 & 1960 & 0.27 & 0.03 \\
${ }^{252}$ Cf (PSI) & 3 & 824 & 0.85 & 0.11 \\
${ }^{252}$ Cf (SCK-CEN) & 3 & 835 & 0.52 & 0.25 \\
\hline
\end{tabular}

Table 3. PADC and FNTD results for the different irradiation conditions (track densities behind fast neutron converter).

\begin{tabular}{|c|c|c|c|c|c|c|c|c|}
\hline $\begin{array}{l}\text { Irradiation \# } \\
\text { source, angle, } \\
\text { distance }\end{array}$ & $H_{t}(\mathrm{mSv})$ & $\begin{array}{l}\text { PADC track } \\
\text { density } \\
\left(\text { tracks cm }^{-2}\right)\end{array}$ & $\begin{array}{c}\text { FNTD track } \\
\text { density } \\
\left(\text { tracks cm }^{-2}\right)\end{array}$ & $\begin{array}{l}\text { FNTD } \\
\text { energy }\end{array}$ & $\begin{array}{c}\text { PADC } \\
H_{m} \\
(\mathrm{mSv})\end{array}$ & $\begin{array}{c}\text { FNTD } \\
H_{m} \\
(\mathrm{mSv})\end{array}$ & $\begin{array}{l}\mathrm{PADC} \\
H_{m} / H_{t}\end{array}$ & $\begin{array}{l}\text { FNTD } \\
H_{m} / H_{t}\end{array}$ \\
\hline \multirow{4}{*}{$\begin{array}{l}11^{252} \mathrm{Cf}+{ }^{137} \mathrm{Cs}, \\
0^{\circ}, 58 \mathrm{~cm}\end{array}$} & \multirow{4}{*}{$\begin{array}{l}1.00(5) \\
(+1 \mathrm{mSv} \gamma)\end{array}$} & 481 & 850 & ${ }^{252} \mathrm{Cf}$ & 1.2 & 1.02 & 1.20 & 1.02 \\
\hline & & 421 & 1060 & ${ }^{252} \mathrm{Cf}$ & 1.05 & 1.28 & 1.05 & 1.28 \\
\hline & & 474 & 950 & ${ }^{252} \mathrm{Cf}$ & 1.18 & 1.15 & 1.18 & 1.15 \\
\hline & & 369 & 820 & ${ }^{252} \mathrm{Cf}$ & 0.92 & 0.99 & 0.92 & 0.99 \\
\hline \multirow[t]{4}{*}{$12^{252} \mathrm{Cf}, 0^{\circ}, 58 \mathrm{~cm}$} & \multirow[t]{4}{*}{$5.00(24)$} & 2147 & 4260 & ${ }^{252} \mathrm{Cf}$ & 5.36 & 5.13 & 1.07 & 1.03 \\
\hline & & 2111 & 4750 & ${ }^{252} \mathrm{Cf}$ & 5.27 & 5.72 & 1.05 & 1.14 \\
\hline & & 2079 & 4460 & ${ }^{252} \mathrm{Cf}$ & 5.18 & 5.37 & 1.04 & 1.07 \\
\hline & & 2097 & 4490 & ${ }^{252} \mathrm{Cf}$ & 5.24 & 5.41 & 1.05 & 1.08 \\
\hline \multirow{4}{*}{$\begin{array}{l}13^{252} \mathrm{Cf}, 0^{\circ}, \\
100 \mathrm{~cm}\end{array}$} & \multirow[t]{4}{*}{$7.00(22)$} & 3092 & 6380 & ${ }^{252} \mathrm{Cf}$ & 7.72 & 7.69 & 1.10 & 1.10 \\
\hline & & 3002 & 6300 & ${ }^{252} \mathrm{Cf}$ & 7.50 & 7.57 & 1.07 & 1.08 \\
\hline & & 3285 & 6610 & ${ }^{252} \mathrm{Cf}$ & 8.20 & 7.97 & 1.17 & 1.14 \\
\hline & & 2993 & 5800 & ${ }^{252} \mathrm{Cf}$ & 7.47 & 6.94 & 1.07 & 0.99 \\
\hline \multirow{6}{*}{$\begin{array}{l}14^{252} \mathrm{Cf}, 30^{\circ}, \\
100 \mathrm{~cm} \\
15^{252} \mathrm{Cf}, 0^{\circ} \\
100 \mathrm{~cm}\end{array}$} & \multirow[t]{2}{*}{$3.50(11)$} & 1063 & 2300 & ${ }^{252} \mathrm{Cf}$ & 2.65 & 2.81 & 0.76 & 0.80 \\
\hline & & 1108 & 2350 & ${ }^{252} \mathrm{Cf}$ & 2.77 & 2.84 & 0.79 & 0.81 \\
\hline & \multirow[t]{4}{*}{$0.30(1)$} & 98 & 330 & ${ }^{252} \mathrm{Cf}$ & 0.24 & 0.40 & 0.80 & 1.33 \\
\hline & & 121 & 290 & ${ }^{252} \mathrm{Cf}$ & 0.30 & 0.35 & 1.00 & 1.17 \\
\hline & & 132 & 480 & ${ }^{252} \mathrm{Cf}$ & 0.33 & 0.58 & 1.10 & 1.94 \\
\hline & & 63 & 220 & ${ }^{252} \mathrm{Cf}$ & 0.16 & 0.27 & 0.53 & 0.90 \\
\hline \multirow{2}{*}{$\begin{array}{l}16^{241} \mathrm{Am}-\mathrm{Be}, 0^{\circ}, \\
100 \mathrm{~cm}\end{array}$} & \multirow[t]{2}{*}{$0.90(5)$} & 344 & 1560 & Uncertain & 0.86 & $1.88^{*}$ & 0.96 & $2.09^{\mathrm{a}}$ \\
\hline & & 316 & 1610 & Uncertain & 0.79 & $1.94 *$ & 0.88 & $2.15^{\mathrm{a}}$ \\
\hline
\end{tabular}

${ }^{a}$ Dose calculated using calibration for ${ }^{252} \mathrm{Cf}$. The calculation was revised using calibration for ${ }^{241} \mathrm{Am}-\mathrm{Be}$ source and the results were 0.90 and $0.92 \mathrm{mSv}$. 


\section{E. G. YUKIHARA ET AL.}

Figure 2 shows The Li/PA and Li/PE ratios. Besides the difference in magnitude and the large uncertainties, similar trends were observed for PADCs and FNTDs. The PADC Li/PA ratio was in general $>8$, and varying with irradiation conditions. Normally the PADC Li/PA ratio is $\sim 1.0$ for irradiation with fast neutrons without phantom, but for irradiations on phantom the track density behind ${ }^{6} \mathrm{LiF}$ chip is 10 times higher than behind PE converter because of the neutrons thermalized by the phantom.

For the FNTDs, the Li/PE ratio varied between 0.14 and 1.00 , but in most cases were $>0.4$. Because of that, most of the dose calculations assumed the ${ }^{252} \mathrm{Cf}$ calibration. The detectors in irradiation \#16 did not provide a sufficient precise estimate for the $\mathrm{Li} / \mathrm{PE}$ ratio due to low statistics and, therefore, the energy was classified as 'uncertain' and the doses were reported using the ${ }^{252} \mathrm{Cf}$ calibration, resulting in a discrepancy of a factor of 2 . These results were later revised with the ${ }^{241} \mathrm{Am}-\mathrm{Be}$ calibration, resulting in agreement with PADC results. Larger FNTD areas could be scanned to improve the counting statistics at low doses.

\section{CONCLUSIONS}

The results presented here provide the first independent comparison between PADC and FNTDs. The results showed an agreement between the two techniques, with an average and maximum differences between PADCs and FNTDs of 1.5 and $22 \%$, respectively, if one compares only cases in which the doses were $>1 \mathrm{mSv}$. For one of the irradiation with dose $<$ $1 \mathrm{mSv}$, use of the incorrect calibration factor $\left({ }^{252} \mathrm{Cf}\right.$ instead of ${ }^{241} \mathrm{Am}-\mathrm{Be}$ ) led to reported values $\sim \times 2$ larger than the given doses for the FNTDs. This was

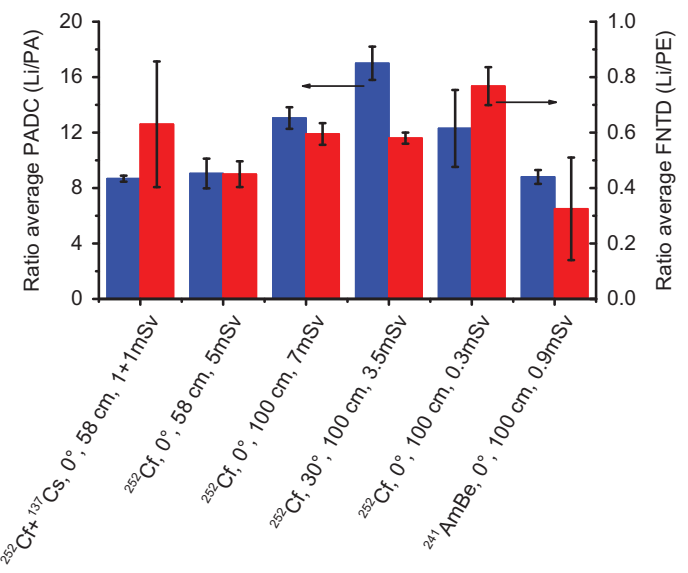

Figure 2. Ratio between the track density behind ${ }^{6} \mathrm{Li}$ converter and PA or PE converter for PADCs and FNTDs, as a function of irradiation condition. caused by the low statistics in the determination of the neutron energy spectrum based on the ratio between ${ }^{6} \mathrm{Li}$ and polyethylene neutron converters, which can be improved by scanning larger FNTD areas. The background discrimination algorithm from the TASLIMAGE system showed good performance, whereas for one unirradiated FNTDs a dose of $0.28 \mathrm{mSv}$ was reported. It is not clear if this was due to the influence of cosmic rays during transport or to the background in the detectors. This study represents only a small set of data-PADCs can also lead to false positives if material problems are not properly handled by the track filtering algorithm.

Although the FNTD track analysis algorithm may need further development, these results provide evidence of the FNTD technology feasibility for neutron dosimetry and indicate areas where improvements are required. At the moment the main disadvantages of the FNTDs in comparison with PADCs are the readout time and the energy response. FNTD measurements tend to sample smaller surface area compared to PADCs, which may lead to larger uncertainties. Enlarging the FNTD scan area can be seen as a major area of improvement. On the one hand, the FNTD readout time is much longer than the PADC readout time, but on the other hand no etching is required. The FNTD energy dependence also requires precise determination of the $\mathrm{Li} / \mathrm{PE}$ ratio, and therefore a larger scanned area for better statistics. If these technical issues are addressed, the main advantage of the FNTDs will be the possibility of re-using the detectors in passive neutron dosimetry.

\section{FUNDING}

This work was partly supported by the Swiss Nuclear Safety Inspectorate (Contract no. H-101196).

\section{ACKNOWLEDGMENTS}

The authors thank Helga Schröter for the detector etching, PTB for the irradiation opportunity, and Filip Vanhavere (SCK.CEN) for additional irradiations.

\section{REFERENCES}

1. ICRU. ICRU Report 66: determination of operational dose equivalent quantities for neutrons. J. ICRU 1(3), 1-93 (2001).

2. Cassou, R. M. and Benton, E. V. Properties and applications of CR-39 polymeric nuclear track detector. Nucl. Track Detect. 2(3), 173-179 (1978).

3. Mayer, S., Assenmacher, F. and Boschung, M. Determination of the response function for two personal neutron dosemeter designs based on PADC. Radiat. Prot. Dosim. 161(1-4), 82-85 (2014). 


\section{COMPARISON BETWEEN PADC AND FNTD NEUTRON DETECTOR SYSTEMS}

4. Fews, A. P. Fully automated image analysis of etched tracks in CR-39. Nucl. Instrum. Methods Phys. Res. B 71(4), 465-478 (1992).

5. Mayer, S. and Boschung, M. Comparison of different PADC materials for neutron dosimetry. Radiat. Prot. Dosim. 161(1-4), 104-107 (2014).

6. Akselrod, M. S. and Akselrod, A. E. $\mathrm{New} \mathrm{Al}_{2} \mathrm{O}_{3}: \mathrm{C}, \mathrm{Mg}$ crystals for radiophotoluminescent dosimetry and optical imaging. Radiat. Prot. Dosim. 119(1-4), 218-221 (2006).

7. Akselrod, M. S., Yoder, R. C. and Akselrod, G. M. Confocal fluorescent imaging of tracks from heavy charged particles utilising new $\mathrm{Al}_{2} \mathrm{O}_{3}: \mathrm{C}, \mathrm{Mg}$ crystals. Radiat. Prot. Dosim. 119(1-4), 357-362 (2006).

8. Akselrod, M. S., Fomenko, V. V., Bartz, J. A. and Haslett, T. L. Automatic neutron dosimetry system based on fluorescent nuclear track detector technology. Radiat. Prot. Dosim. 161(1-4), 86-91 (2014).

9. Sykora, G. J., Salasky, M. and Akselrod, M. S. Properties of novel fluorescent nuclear track detectors for use in passive neutron dosimetry. Radiat. Meas. 43, 1017-1023 (2008).

10. Schuhmacher, H. et al. Evaluation of individual dosimetry in mixed neutron and photon radiation fields (EVIDOS). Part II: conclusions and recommendations. Radiat. Prot. Dosim. 125(1-4), 281-284 (2007).

11. Boschung, M., Fiechtner, A., Mayer, S. and Wernli, C. Field calibration and comparison of personal neutron dosemeter designs based on CR-39 for the use around high-energy accelerators. Radiat. Meas. 43(2-6), 1081-1084 (2008).

12. Hoedlmoser, H., Schuler, C., Butterweck, G. and Mayer, S. Characteristics of the neutron irradiation facilities of the PSI calibration laboratory. In: AIP Conference Proceedings, 1412, 385-392 (2011).

13. Fomenko, V. V., Moreno, B., Million, M., Harrison, J. and Akselrod, M. S. Energy Response of FNTD dosimeters to monoenergetic neutron fields. Radiat. Prot. Dosim. (2017) Submitted. 